\title{
Perceived Notions of Academic Leaders about Leadership Capabilities for effective performance of Health Sciences Institutes
}

\author{
Kalidas Dattatraya Chavan \\ Post Doctoral Fellow, College of Allied Health Sciences, \\ Shrinivas University, Mangaluru, Karnataka, India- 575001. \\ Email: kdchavan17@gmail.com
}

Area/Section: Health Sciences.

Type of the Paper: Research Paper.

Type of Review: Peer Reviewed as per $|\mathrm{C}| \mathrm{O}|\mathrm{P}| \mathrm{E} \mid$ guidance.

Indexed in: OpenAIRE.

DOI: http://doi.org/10.5281/zenodo.3613373.

Google Scholar Citation: IJHSP

\section{How to Cite this Paper:}

Chavan., Kalidas Dattatraya. (2019). Perceived Notions of Academic Leaders about Leadership Capabilities for effective performance of Health Sciences Institutes. International Journal of Health Sciences and Pharmacy (IJHSP), 3(2), 16-22.

DOI: https://doi.org/10.5281/zenodo.3613373.

International Journal of Health Sciences and Pharmacy (IJHSP)

A Refereed International Journal of Srinivas University, India.

IFSIJ Journal Impact Factor for 2019-20 = 3.968

(C) With Author.

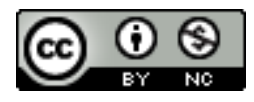

This work is licensed under a Creative Commons Attribution-Non Commercial 4.0 International License subject to proper citation to the publication source of the work.

Disclaimer: The scholarly papers as reviewed and published by the Srinivas Publications (S.P.), India are the views and opinions of their respective authors and are not the views or opinions of the SP. The SP disclaims of any harm or loss caused due to the published content to any party. 


\title{
Perceived Notions of Academic Leaders about Leadership Capabilities for effective performance of Health Sciences Institutes
}

\author{
Kalidas Dattatraya Chavan \\ Post Doctoral Fellow, College of Allied Health Sciences, \\ Shrinivas University, Mangaluru, Karnataka, India- 575001. \\ Email :kdchavan17@gmail.com
}

\begin{abstract}
Educational leadership is essential for competitive health sciences education environment. In order to develop a supportive and collaborative environment in health sciences education institutions, various skills and abilities required among academic leaders. There is lack of consensus about the exact characteristics of a successful leader in higher education. In order to reinforce leadership qualities in academic leaders in the context of higher education and identify various perceptions about leadership qualities as perceived by academic leaders of health sciences institutes a cross sectional study has been conducted in Health Sciences Institutes /Universities offering formal degree programs of various institutes in the state of Maharashtra during August 2019 to December 2019. The study population was the academic leaders in the health sciences institutions serving in different capacities starting from Heads of the academic departments in a college, Dean/Principals of the colleges and vice chancellors of the universities. Study concluded that, the academic leaders of the health sciences institutes have better understanding about the leadership capabilities required for effective performance of health sciences institutions. The perceptions of academic leaders revealed that understanding personal strengths and limitations is most important personal capability, transparency and honestywhile dealing with others is most important Interpersonal Capability and thinking creatively and laterally is important among Intellectual Capabilities.
\end{abstract}

Keywords:Academic leadership, Health sciences institutes,Personal capability, Interpersonal capability, Intellectual capabilities.

\section{INTRODUCTION :}

Academic leadership involves demonstrating qualities and behaviours, which relate to values and identities within either informal or formal contexts. However, academic management involves allocating tasks and enacting institutional processes usually within a formal context[1].Leadership activity is seen as intertwined with management (and administration). Although, academic leadership and management are interwoven and complementary and shows 'a symbiotic relationship[2], academic leadership have several dimensions as compare to academic management. The educational leadership theory is multidimensional, complex and dynamic. The pervasiveness of the notion of leadership has fascinated leadership researchers to capture, analyze and interpret the leadership essence in higher education from various dimensions. In last few years, the studies have highlighted the change, adjustment and turbulent environment in the higher education along with diversity in the departments, universities and leaders. Effective educational leadership can be seen as one of the greatest benefits that a university can have in a resource-hungry, competitive higher education environment [3].

Higher education leadership literature includes qualities of academic leadership including passion, courage, integrity, trustworthiness, adaptability, accountability, consideration, creatinga healthy working atmosphere, be ready to support and accept necessary support, and be able to positively influential on others[4].

Debowski and Blake[5] have emphasized that 
academic leaders of higher education institutes need common characteristics which are important for delivering leadership roles for example, to develop a collaborative and supportive culture and collaborators and ability to provide knowledge sharing opportunities. The skill sets, working abilities and knowledge required for departmental heads in the large universities was studied by Aziz et. al. [6]. In spite of the fact that several studies have identified leadership as a concrete and observable phenomenon, there is no consensus yet on the exact characteristics of a successful leader in higher education. Current academic leaders have different perceptions about the educational qualities required for educational excellence. If thinking and perceptions about qualities are identified, it will help to reinforce leadership qualities in academic leaders in the context of higher education. So, this study was planned to identify various perceptions about leadership qualities as perceived by academic leaders of health sciences institutes.

\section{METHODOLOGY :}

Study Design -This study was a subset of larger cross-sectional study to determine the perception of the academic leaders on academic leadership.

Study Setting - The study setting was Health Sciences Institutes /Universities offering formal degree programs of various disciplines in the state of Maharashtra including state funded, private and those affiliated to deemed to be universities.

Study Period: The study was conducted from August, 2019 to December, 2019.

Study Population: The study population for the current study was the academic leaders in the health sciences institutions serving in different capacities starting from Heads of the academic departments in a college, Dean/Principals of the colleges and vice chancellors of the universities.

Sample Size -About $15 \%$ of the available academic leaders were initially invited to participate in the study. Considering a third of them will drop out and two third will participate, final sample consisted minimum $10 \%$ of the total available academic leaders. There were about 10 deemed to be Universities, one State University and about
398 health science institutes in the state. Vice chancellors of 3 Universities were included in the study. However, minimum $10 \%$ Deans/Principal's and HOD's were included in the study. Hence, the total sample size for the study was 3 Vice Chancellor, 43 Dean's/Principal's and 416 HOD's.

Sampling Technique-The list of all eligible personnel those fit in the definition of academic leaders along with their contact details was collected and compiled from various sources. From this list the required number of participants were selected using simple random sampling technique.

Data Collection and Analysis- The main objective of the study was to understand the perceptions of leadership capabilities under four categories i.e. Personal capabilities, Interpersonal capabilities, Intellectual capabilities and Skills Proficiency of the academic leaders[7]. Accordingly, the data collection tool was developed and validated taking into consideration the important capabilities. Selected participants were invited to participate in the study by sending an online link to fill the survey questionnaire on 1 to 5 Likert scale. Data was collected through online questionnaire. The analysis was performed using SPSS.

\section{RESULTS AND DISCUSSION :}

The study received response from 687 academic leaders out of which 318 were females which is $46.3 \%$ of total respondents and 369 were males which is $53.7 \%$ of total respondents. $79 \%$ academic leaders from present study were holding a post graduate degree i.e. M.Sc./MD/MS/DNB/DM/MCH/MDS and only $21 \%$ academic leaders were holding Ph.D. degree. Maximum respondents i.e. 31.1 $\%$ were from Ayurveda discipline followed by Nursing (22.1 \%), Homoeopathy (18.2 \%), Modern Medicine (13.4\%), Allied Health (9 $\%)$ and Dentistry (6.1\%).

\subsection{Leadership Capabilities for effective performance:}

The capabilities which are identified in the present study and on which the perceptions were collected from the academic leaders are similar with attributes of effective higher education leaders. 
(1) Personal Capabilities:

For certain times, it really becomes important for leaders to be able to control and manage their emotional behaviour to uncertainty and distress[7]. Most of the respondents (221 out of 687, $32.2 \%$ ) perceived "understanding personal strength and limitations" as the most important personal capability for effective performance in their current academic leadership role. "Being Confident" was the next important capability as perceived by 32.6 $\%$ respondents. $40 \%$ respondents perceived that taking responsibilities during functioning as an academic leader is at the third position for effective performance. Wanting to achieve the best outcome possible was ranked at fourth level by $41.8 \%$ respondents and $60.1 \%$ respondents perceived that bouncing back from adversity is less important personal capability for effective performance in their current role. Kendall's W was 0.153, signifying less degree of agreement amongst the participants. Extensive research has already been done on the personal and interpersonal abilities of the leaders in past decade by researchers such as Goelman[8] and often referred to as the 'emotional intelligence' of a leader.

Passion, enthusiasm and energy towards learning and teaching was ranked 1 and wanting to achieve the best outcome possible was ranked 2 by the respondent from the study conducted by Majid Ghasemy[9]. In a study of academic leadership capabilities of teachers conducted in Myanmar the highest responses in the current personal capabilities of the respondents were received on passion, energy and enthusiasm towards learning and teaching[10].

Table 1: Ranking by the respondents for various personal capabilities for effective performance in their current role

\begin{tabular}{|c|c|c|c|c|c|c|c|c|c|c|c|}
\hline \multirow{2}{*}{ SI } & \multirow{2}{*}{$\begin{array}{c}\text { Personal } \\
\text { Capability }\end{array}$} & \multicolumn{2}{|c|}{ Rank 1} & \multicolumn{2}{|c|}{ Rank 2} & \multicolumn{2}{|c|}{ Rank 3} & \multicolumn{2}{|c|}{ Rank 4} & \multicolumn{2}{|c|}{ Rank 5} \\
\hline & & $\mathbf{N}$ & $\%$ & $\mathbf{N}$ & $\%$ & $\mathbf{N}$ & $\%$ & $\mathbf{N}$ & $\%$ & $\mathbf{N}$ & $\%$ \\
\hline 1 & $\begin{array}{l}\text { Understanding } \\
\text { personal strengths } \\
\text { and limitations }\end{array}$ & 221 & 32.2 & 147 & 21.4 & 137 & 19.9 & 93 & 13.5 & 89 & 13.0 \\
\hline 2 & Being Confident & 143 & 20.8 & 224 & 32.6 & 145 & 21.1 & 134 & 19.5 & 41 & 6.0 \\
\hline 3 & $\begin{array}{l}\text { Taking } \\
\text { Responsibilities }\end{array}$ & 129 & 18.8 & 158 & 23.0 & 275 & 40.0 & 79 & 11.5 & 46 & 6.7 \\
\hline 4 & $\begin{array}{l}\text { Wanting to achieve } \\
\text { the best outcome } \\
\text { possible }\end{array}$ & 79 & 11.5 & 130 & 18.9 & 93 & 13.5 & 287 & 41.8 & 98 & 14.3 \\
\hline 5 & $\begin{array}{l}\text { Bouncing back } \\
\text { from adversity }\end{array}$ & 115 & 16.7 & 28 & 4.1 & 37 & 5.4 & 94 & 13.7 & 413 & 60.1 \\
\hline
\end{tabular}

(2) Interpersonal Capabilities :

Most of the participants (296 out of 687, 43.1\%) perceived "Being transparent and honest in dealing with others" as the most important interpersonal capability for effective performance in their current role. "Empathizing and working positively with staff" was the next important capability, as perceived by $30.9 \%$ respondents. 34. $8 \%$ respondents ranked developing and contributing positively in team based programs on third number followed by Listening to different point of views before coming to decision at fourth number by $28.7 \%$ respondents. $41 \%$ respondents perceived that
Empathizing and working positively with staff has got least priority on five point scale as an interpersonal capability for effective performance. However, the Kendall's W was 0.067, signifying the less degree of agreement amongst the participants. The outcome of the study is similar to the study conducted by Majid Ghasemy[9]. He reported that being transparent and honest in dealings with others was rated first rank. 
Table 2: Rankings by the participants for various interpersonal capabilities for effective performance in their current role

\begin{tabular}{|c|c|c|c|c|c|c|c|c|c|c|c|}
\hline \multirow{2}{*}{ SI } & \multirow{2}{*}{$\begin{array}{l}\text { Interpersonal } \\
\text { Capability }\end{array}$} & \multicolumn{2}{|c|}{ Rank 1} & \multicolumn{2}{|c|}{ Rank 2} & \multicolumn{2}{|c|}{ Rank 3} & \multicolumn{2}{|c|}{ Rank 4} & \multicolumn{2}{|c|}{ Rank 5} \\
\hline & & $\mathbf{N}$ & $\%$ & $\mathbf{N}$ & $\%$ & $\mathbf{N}$ & $\%$ & $\mathbf{N}$ & $\%$ & $\mathbf{N}$ & $\%$ \\
\hline 1 & $\begin{array}{l}\text { Being transparent and } \\
\text { honest in dealing with } \\
\text { others }\end{array}$ & 296 & 43.1 & 116 & 16.9 & 86 & 12.5 & 74 & 10.8 & 115 & 16.7 \\
\hline 2 & $\begin{array}{l}\text { Motivating others to } \\
\text { achieve goals }\end{array}$ & 87 & 12.7 & 212 & 30.9 & 144 & 21.0 & 154 & 22.4 & 90 & 13.1 \\
\hline 3 & $\begin{array}{l}\text { Developing and } \\
\text { contributing positively } \\
\text { in team based programs }\end{array}$ & 95 & 13.8 & 130 & 18.9 & 239 & 34.8 & 133 & 19.4 & 90 & 13.1 \\
\hline 4 & $\begin{array}{l}\text { Listening to different } \\
\text { point of views before } \\
\text { coming to decision }\end{array}$ & 85 & 12.4 & 159 & 23.1 & 136 & 19.8 & 197 & 28.7 & 110 & 16.0 \\
\hline 5 & $\begin{array}{l}\text { Empathizing and } \\
\text { working positively with } \\
\text { staff }\end{array}$ & 124 & 18.0 & 70 & 10.2 & 82 & 11.9 & 129 & 18.8 & 282 & 41.0 \\
\hline
\end{tabular}

\section{(3)Intellectual Capabilities:}

About 233 out of 687 (33.9\%) respondents perceived "Thinking creatively and laterally" as the most important intellectual capability for effective performance in their current role. "Setting and justifying priorities of work" was also ranked one as important capability, as perceived by $32.5 \%$ respondents. $42.8 \%$ respondents perceived that making sense of learning from experiences is the third important capability for effective performance as an academic leader. Adjusting plan of action in response to the problems encountered while implementing was given fourth rank by maximum respondents i.e. $37.3 \%$ and Assessing the likely outcome of course of action was perceived as least important intellectual capability by $45.7 \%$ respondents. Kendall's W was 0.13, signifying the less degree of agreement amongst the participants. In the study conducted by Mary Jacqueline et.al. [10], they reported highest current cognitive capability of the respondents is on learning from experience and second highest current cognitive capability they reported is setting priorities for their daily. However, Majid Ghasemy[9]have reported that thinking creatively and laterally was ranked at 3 by the respondents and Setting and justifying priorities for daily work was ranked at 5 .

Table 3: Ranking by the respondents for various intellectual capabilities for effective performance in their current role

\begin{tabular}{|l|l|l|l|l|l|l|l|l|l|l|l|l|}
\hline \multirow{2}{*}{ SI } & Intellectual & \multicolumn{2}{|l|}{ Rank 1 } & \multicolumn{2}{l|}{ Rank 2 } & \multicolumn{2}{l|}{ Rank 3 } & \multicolumn{2}{|l|}{ Rank 4 } & \multicolumn{2}{l|}{ Rank 5 } \\
\cline { 2 - 13 } & Capability & $\mathbf{N}$ & $\mathbf{\%}$ & $\mathbf{N}$ & $\mathbf{\%}$ & $\mathbf{N}$ & $\mathbf{\%}$ & $\mathbf{N}$ & $\mathbf{\%}$ & $\mathbf{N}$ & $\mathbf{\%}$ \\
\hline 1 & $\begin{array}{l}\text { Thinking creatively } \\
\text { and laterally }\end{array}$ & 233 & 33.9 & 175 & 25.5 & 96 & 14.0 & 77 & 11.2 & 106 & 15.4 \\
\hline 2 & $\begin{array}{l}\text { Setting and justifying } \\
\text { priorities of work }\end{array}$ & 223 & 32.5 & 211 & 30.7 & 98 & 14.3 & 104 & 15.1 & 51 & 7.4 \\
\hline 3 & $\begin{array}{l}\text { Making sense of } \\
\text { learning from } \\
\text { experiences }\end{array}$ & 69 & 10.0 & 101 & 14.7 & 294 & 42.8 & 123 & 17.9 & 100 & 14.6 \\
\hline
\end{tabular}




\begin{tabular}{|l|l|l|l|l|l|l|l|l|l|l|l|}
\hline 4 & $\begin{array}{l}\text { Adjusting plan of } \\
\text { action in response to } \\
\text { the problems } \\
\text { encountered while } \\
\text { implementing. }\end{array}$ & 60 & 8.7 & 129 & 18.8 & 126 & 18.3 & 256 & 37.3 & 116 & 16.9 \\
\hline 5 & $\begin{array}{l}\text { Assessing the likely } \\
\text { outcome of course of } \\
\text { action. }\end{array}$ & 102 & 14.8 & 71 & 10.3 & 73 & 10.6 & 127 & 18.5 & 314 & 45.7 \\
\hline
\end{tabular}

(4)Skill Proficiency:

In order to cope effectively with frequent organizational changes, the leaders of modern day need to understand and know the skill, abilities and knowledge[11]. It is expected during the process of getting educational degree that the management schools will definitely impact the management practice when it is capable of training particular skills set which is associated with the management task [12].

Table 4: Ranking by the respondents for various skills for effective performance in their current role

\begin{tabular}{|c|c|c|c|c|c|c|c|c|c|c|c|}
\hline \multirow{2}{*}{ SI } & \multirow{2}{*}{ Skills Proficiency } & \multicolumn{2}{|c|}{ Rank 1} & \multicolumn{2}{|c|}{ Rank 2} & \multicolumn{2}{|c|}{ Rank 3} & \multicolumn{2}{|c|}{ Rank 4} & \multicolumn{2}{|c|}{ Rank 5} \\
\hline & & $\mathbf{N}$ & $\%$ & $\mathbf{N}$ & $\%$ & $\mathbf{N}$ & $\%$ & $\mathbf{N}$ & $\%$ & $\mathbf{N}$ & $\%$ \\
\hline 1 & $\begin{array}{l}\text { Skill to implement a } \\
\text { new educational } \\
\text { program effectively }\end{array}$ & 245 & 35.7 & 124 & 18.0 & 106 & 15.4 & 96 & 14.0 & 116 & 16.9 \\
\hline 2 & $\begin{array}{l}\text { Being able to use } \\
\text { Information } \\
\text { Communication } \\
\text { technology }\end{array}$ & 113 & 16.4 & 184 & 26.8 & 133 & 19.4 & 153 & 22.3 & 104 & 15.1 \\
\hline 3 & $\begin{array}{l}\text { Ability to chair } \\
\text { meetings effectively }\end{array}$ & 95 & 13.8 & 122 & 17.8 & 215 & 31.3 & 126 & 18.3 & 129 & 18.8 \\
\hline 4 & $\begin{array}{l}\text { Ability to develop } \\
\text { policy documents }\end{array}$ & 83 & 12.1 & 155 & 22.6 & 125 & 18.2 & 202 & 29.4 & 122 & 17.8 \\
\hline 5 & $\begin{array}{l}\text { Skills of resource } \\
\text { management. }\end{array}$ & 151 & 22.0 & 102 & 14.8 & 108 & 15.7 & 110 & 16.0 & 216 & 31.4 \\
\hline
\end{tabular}

Kendall's W $=0.0263$

About 245 out of 687 (35.7\%) respondents perceived "Skill to implement a new educational program effectively" as the most important skill for effective performance in their current role. "Skills of resource management" was the next important skill, as perceived by $26.8 \%$ respondents. $31.3 \%$ respondents perceived that Ability to chair meetings effectively is third important Skills Proficiency required for effective performance in health science institutes. Ability to develop policy documents was recognized as fourth important skill proficiency by $29.4 \%$ respondents followed by $31.4 \%$ respondents who perceived Skills of resource management is the least important skill proficiency required for effective performance. Kendall's W was
0.0263, signifying the less degree of agreement amongst the participants. Ability of using information technology in a better and effective manner to communicate and do key functions was given seventh rank by the respondents in the study conducted by Majid Ghasemy[9]. This was ranked 2 in the present study. The potential to head the meetings effectively was ranked 3 in the same study and Having sound administrative and resource management skills was ranked 4 . Hence, most of the outcomes of the study are in accordance with thestudy conducted by Majid Ghasemy[9].

\section{CONCLUSION :}

It is concluded from present study that; the academic leaders of the health sciences 
institutes have better understanding about the leadership capabilities required for effective performance of health sciences institutions. As per the perceptions of academic leaders, understanding personal strengths and limitations is most important personal capability, being transparent and honest in dealing with others is most important Interpersonal Capability and thinking creatively and laterally is important among Intellectual Capabilities.Under the Skill set to implement a new educational program effectively is most important skill for academic leaders.

\section{REFERENCES :}

[1] Bolden, R., Gosling, J., O’Brien, A., Peters, K., Ryan, M., \& Haslam (2012).Academic leadership: Changing conceptions, identities and experiences in UK higher education. London: LFHE.

[2] McCaffery, P (2010). The higher education manager's handbook: Effective leadership and management in universities and colleges (2nd ed.).Abingdon: Routledge.

[3] Ramsden, P. (1998).Learning to lead in higher education. London: Routledge. 1998.

[4] Drew G. (2006). Balancing Academic Advancement with Business Effectiveness? International Journal of Knowledge, Culture and Change Management. 6(4), available from: http://www.ManagementJournal.com.

[5] Debowski D. \& Blake V. (2004). The developmental needs of higher education academic leaders in encouraging effective teaching and learning. Seeking Educational Excellence, Teaching and Learning Forum. University of WA.

[6] Aziz, S., Mullins, M., Balzer, W., Grauer, E., Burnfield, J., Lodato, M., \& CohenPowless, M. (2005). Understanding the training needs of department chairs. Studies in Higher Education. 30(5), 571593.

[7] Scott Geoff, Hamish Coates \& Michelle Anderson (2008). Learning Leaders in times of Change-Academic Leadership Capabilities for Australian Higher
Education. University of Western Sydney and Australian Council for Educational Research. 2008. ISBN: 978-0-86431-9784.

[8] Goleman Daniel (2000). An EI-Based Theory of Performance. The emotionally intelligent workplace : how to select for, measure, and improve emotional intelligence in individuals, groups, and organizations / by Cary Cherniss, Daniel Goleman, editors.-1st ed. 2000.

[9] MajidGhasemy (2017). Capabilities and Competencies Related to Leadership Performance Effectiveness in the Context of Change in Malaysian Higher Education Institutions. Thesis Submitted in Fulfilment of the Requirements for the degree of Doctor of Philosophy in Educational Management, Faculty of Education, University of Malaya, Kuala Lumpur.

[10] Mary Jacqueline and Kanog-on Rungrojngarmcharoen (2014). A study of academic leadership capabilities of teachers in a selected no. 2 basic education high school in Myanmar. Scholar: Human Sciences, 6(2).

[11] Elham Shahmandi (2011). Competencies, Roles and Effective Academic Leadership in World Class University. International Journal of Business Administration, 2(1),44-53.

[12] Mintzberg H. (1973). The nature of managerial work. NY: Harper \& Row. 